\title{
DE HISTORIAS, MEDIOS Y REGIÓN: UNA IMPRONTA DESDE LA PRODUCCIÓN AUDIOVISUAL
}

\author{
NORA DELGADO \\ Universidad Nacional de Misiones, \\ Posadas, Misiones, Argentina \\ e - mail: nora_delgado@hotmail.com
}




\section{HISTÓRIAS, MÍDIA E REGIÃO: UMA MARCA DA PRODUÇÃO AUDIOVISUAL}

Resumo: Este artigo irá focar os olhos na produção audiovisualista desenvolvido na cidade de Posadas, a partir da criação da Universidade Nacional de Misiones. Esta definição, em seguida, inclui a elaboração de um indivíduo e audiovisualista criativo: Discussão de fazer audiovisualista Rodolfo Nicholas Capaccio Desde a sua obra de "praticante cultural" e de seus registros, delimitados, analisados e um projeto cultural que contém ocorre a região, mas também é contido por ela. Palavras-chave: Comunicação; Meios Audiovisuais; História.

\section{DE HISTORIAS, MEDIOS Y REGIÓN: UNA IMPRONTA DESDE LA PRO- DUCCIÓN AUDIOVISUAL}

Resumen: Este articulo focalizará la mirada en la producción audiovisualista desarrollada en la ciudad de Posadas, a partir de la creación de la Universidad Nacional de Misiones. Esta delimitación, entonces, comprenderá el hacer de un audiovisualista particular y creativo: hablo del hacer del audiovisualista Rodolfo Nicolás Capaccio Desde su labor de "practicante cultural" y desde sus registros, se delimita, se analiza y se produce un proyecto cultural que contiene a la región pero a la vez es contenido por ella. Palavras-chave: Comunicación; Medios Audiovisuales; Historia.

STORIES, MEDIA AND REGION: AN IMPRINT FROM THE AUDIOVISUAL PRODUCTION

Abstract: This article will focus his eyes on the audiovisualista production developed in the city of Posadas, from the creation of the National University of Misiones. This definition, then include the making of an individual and creative audiovisualista:talk ofmakingaudiovisualista Rodolfo Nicholas CapaccioSince its work of "cultural practitioner " and from their records, delimited, analyzed and a cultural project that contains occurs the region but also is contained by it.

Keywords: Communication; Media; History. 
El presente trabajo surge como una continuidad de la etapa de estudio iniciada previamente en el proyecto de investigación "Comunicación, arte y ciudad: de la gestión cultural” -acreditado en la etapa anterior en la Secretaría de Investigación y Postgrado -SiyP- de la Facultad de Humanidades y Ciencias Sociales -FHyCS- de la Universidad Nacional de Misiones - UNaM- Fue un estudio que posibilitó descripciones semio-comunicativas de este campo de producción cultural, la identificación de actores sociales que hacían y “empujaban” esta práctica en la ciudad de Posadas, más el análisis y la significación de ciertas "matrices culturales" que operaban al interior de este campo de producción cultural, y la identificación de proyectos culturales gestionados en Posadas y en la región.

Esta vez, nuestro intento, focalizará la mirada en la producción audiovisualista desarrollada en la ciudad de Posadas, a partir de la creación de la Universidad Nacional de Misiones. Esta delimitación, entonces, comprenderá el hacer de un audiovisualista particular y creativo: hablo del hacer del audiovisualista Rodolfo Nicolás Capaccio Desde su labor de "practicante cultural" y desde sus registros, se delimita, se analiza y se produce un proyecto cultural que contiene a la región pero a la vez es contenido por ella. Esa propuesta materializada en una discursividad audiovisual, vehiculiza y exhibe, en distintas temporalidades, producciones artísticas, educativas en Posadas, en Misiones y en el resto de la Argentina -en las ciudades en las que se difundió y proyectó esta labor audiovisual (por ejemplo, Buenos Aires, Mendoza, Corrientes, por citar algunas)-.

Mayormente, esas producciones audiovisuales de Rodolfo Capaccio nos hablan de la región y a la vez son habladas por ella en los usos, apropiaciones, y prácticas que posibilitan la gestión cultural (pública y privada de esas expresiones) y el "agenciamiento" para que surgieran algunas y se obturaran -transitoriamente- otras expresiones del campo.

La realidad nuestra de cada día y nuestro quehacer cotidiano entre relatos y medios nos dicen que sabemos de la articulación entre palabra e imagen, entre sonido y texto. Hay saberes y presunciones, algunos develados otros opacados. Hay datos y conocimiento. Hay experiencias y relatos: Hay imágenes, fotos y hay un gran dispositivo de enunciación: la diégesis (la mediática y la cotidiana) que nos permite transitar el curso de una historia y también advertir - como se gusta decir hoy-visibilizar la recursividad de la misma.

Recursividad que no implica desandar la cinta hacia atrás como una pe- 


\section{DE HISTORIAS, MEDIOS Y REGIÓN: UNA IMPRONTA DESDE LA PRODUCCIÓN AUDIOVISUAL}

lícula que debería empezar de nuevo, sino más bien ver esa historia en el contexto actual que inscribe esa historia.

Hacer lo anterior "recursar la historia" es más o menos lo que recursar implica: un volver a cursarla, esto es a darle curso nuevamente pero desde otra temporalidad y otras miradas -porque sino sería nada más que cursarla- ; es volver a pasarla, a transitarla con algunas pistas. Implica meterla en el cauce en que esta se produjo, advertir ahí los disparadores de la misma, la materialidad con que se escribió, descubrir y dar voz y rostro y texto a sus protagonistas. Es -como me refirió un alumno, no sólo describirla sino desenmadejarla-

Y esta historia que les propongo hoy -para darle de nuevo curso- es una historia de proyectos pero lo es además de una situación de gestión y de gestores y a la vez también de ideas y acciones en torno a la cultura y la comunicación.

Gestión, gestores, cultura, comunicación, proyectos son palabras claves que habilitan el anclaje y relevo (explicativo, referencial, detallista) de toda una trama.

Lejos de ser la plana hoja de detalles que activan senderos por dónde -se dice y se nos dice a quienes a veces osamos andar por ahí que se activa la planificación de proyectos en tanto articulen propuestas matriciales del tipo FODA ( y entonces solemos hablar de fortalezas, oportunidades, debilidades y amenazas) y otras sugerencias de otro tipo como las contenidas en objetivos iniciales reforzados concienzudamente en infinitivos-; bueno, les decía que lejos de ser llano este relato, éste va a estar más bien del lado de lo narrado y de las subjetividades que expresan una historia de comunicación -historia en comunicación-, de gestíon cultural y de propuestas concretas para hacer-ser un proyecto. En nuestro caso hacer-ser un proyecto audiovisual.

Como todo proyecto que se precie de ser posible éste guarda la encarnadura de sujetos que actuaron en un espacio y tiempo determinados, guiados por una intuición creativa pero también por un imaginario social-educativo que activara visiones y rescates de un patrimonio cultural ( $y$ vale la aclaración: patrimonio tangible para los habitantes del entorno hacedores de la cultura, pero intangible -muchas veces- para los administradores de ella en ese momento).

Si bien hablo de un tiempo que ya fue y debo aclarar que mi anclaje enunciativo se remonta a la década del ochenta, en la provincia de Misiones, 
y cuando la Universidad Nacional de Misiones, la UNaM, tenía aproximadamente 10 años de creación y todo estaba justamente -como decimos allá- “ por verse" ( y lo decimos precisamente para expresar la idea de un despliegue que recién empezaba) ; bueno, en esa temporalidad del "por verse" un grupo de docentes que se desempeñaban en la que después devino en Secretaría General de Extensión (SGEU) de la- entonces niña- UNaM hizo suyo el "por verse" y dio visibilidad y forma a una propuesta audiovisual para hacer conocer a la Universidad Nacional de Misiones no sólo al interior de la provincia, sino también al resto del país.

¿Cómo lo hicieron? Esta historia recursada permite advertir que "el por verse" de nuestros inicios se transformó en un "verse por", lo que equivale a decir verse a través de... Pero ¿cómo lo hicieron? Lo hicieron generando un producto. Esta propuesta recibió el nombre de Audiovisuales de la Secretaría General de Extensión . Y todavía hoy, ya a casi cuarenta años de aquellos hechos, son evocados estos trabajos en el entorno como iniciáticos, fundacionales, o como algún docente de las carreras de comunicación social de la zona los refiriera "como la arqueología de los documentales en la actualidad".

Dice el testimonio recogido en campo:

"En 1979, año en el que ingresé a la UNaM como docente de la Facultad de Humanidades ( que tiempo después sería de Humanidades y Ciencias Sociales) realicé a pedido del rector (Carlos Roko) algunas olvidables experiencias en cortos promocionales para televisión vinculados con actividades de la Universidad. Estos cortos se filmaron con el equipamiento técnico y humano de canal 12, con lo cual ya de entrada la Universidad quedaba supeditada al arbitrio de lo que dispusiese el Canal que convertía, por su desinterés, mediocridad y burocracia, a estas producciones en un trabajo de gestión más que de producción real. La universidad contra lo que pudiera pensarse no tenía reconocimiento alguno en ese ámbito y la referencia mayor como institución educativa era el Instituto Montoya" '.

El testimonio precedente corresponde al pionero y mayor realizador audiovisual que tuvo la Universidad Nacional de Misiones. Su nombre es Rodolfo Nicolás Capaccio. Fue él quien gestó el proyecto audiovisual de la UNaM con el propósito de darla a conocer, de hacerla pública en el ámbito

\footnotetext{
1 Fragmentos de testimonios del realizador audiovisual Nicolás Capaccio, obtenidos en campo
} 


\section{DE HISTORIAS, MEDIOS Y REGIÓN: UNA IMPRONTA DESDE LA PRODUCCIÓN AUDIOVISUAL}

provincial pero también fuera de la provincia de Misiones, bajo una particular modulación de imagen y sonido.

En contexto, con lo anteriormente explicitado en párrafos anteriores, es inevitable hacer referencia a la acción fecunda y pionera de la SGEU, que ha posibilitado el registro de catorce realizaciones audiovisuales (entre 1980 y 1986), de las cuales han sido presentadas públicamente - a la ciudad y a la provincia de Misiones- diez : Los Personajes de Juan de Dios Mena, La Empresa Jesuítica en Misiones, Los Parientes del Chaco, Los días de Posadas, A la Pintura, Memoria de Madera, Nervaduras, La Selva y el Secreto, El Canto resplandeciente, Yvyraretá (Tierra de los árboles).

Hubo además cuatro proyectos audiovisuales que no completaron la etapa de presentación final, esto es de estreno ciudadano. Fueron no obstante nombrados y registrados dentro del inventario la SGEU. Son: el Proyecto Audiovisual sobre la Isla Caraguatay; Eugenio Benítez en la orilla; El sueño de San Ignacio, Reflejo y bruma. De todas estas prolíficas y exquisitas realizaciones audiovisuales (de autoría de Rodolfo Capaccio) hemos encontrado en campo (a la fecha) solamente dos completas y editadas: el Audiovisual de Las Tallas de Juan de Dios Mena y el de Horacio Quiroga: la selva y el secreto.

Todavía hoy, ya a casi cuarenta años de aquellos hechos, son evocados estos trabajos en el entorno como iniciáticos, fundacionales, o como algún docente de las carreras de comunicación social de la zona los refiriera "como la arqueología de los documentales en la actualidad"

Lejos, de cuestionar tal aseveración, vale la referencia de que los ritmos de lo residual y lo emergente (al estilo Raymond Williams) hacen que -aún hoy en plena vigencia de la imagen digital- se vuelva al tono de esas modulaciones iniciales, en las que las fotos, la música y el texto del guión, formaban un todo performativo contundente.

Hay en estas producciones una importancia asignada al lenguaje asociado a la imagen, a su potencialidad para construir mundos y sentidos, pero fundamentalmente a su condición performativa, como bien lo expresa Leonor Arfuch ${ }^{2}$ cuando piensa este tiempo y "a esa fuerza de la nominación y lo inescindible de la dimensión poética y retórica" afirma.

"Estas coincidencias en cuanto a las concepciones del lenguaje y la discursividad social, también se manifiestan en otros aspectos, tal como puede

2 Cf ARFUCH, Leonor (2005),Pensar este tiempo, Paidós, Buenos Aires. 
verse en la trama de referencias compartidas y los reconocimientos recíprocos. Así y más allá de los temas y enfoques de cada uno, la intertextualidad depara sorpresas no menos estimulantes: se trata de todo un mapa de lecturas, reapropiaciones e interpretaciones que se despliega allí, bajo los ojos, trazando un perfil peculiar del campo epistémico contemporáneo"3 .

Valen sólo como referencia de que se mantiene este lazo no sólo las actuales presentaciones de power point (que han agilizado y mucho este tipo de producción - o los programas informáticos de flash adobe, etc-) sino también los formatos que se incrustan en informativos periodísticos, en programas de opinión y/o entretenimiento (del tipo "Plan M" conducido por Maximiliano Montenegro - emitido por Canal 26" donde los informes que presenta se basan en la edición de fotos, más texto con voz en off y música o los que también se usan en Intratables -por mencionar algunos de los programas que se emiten por cable o en programas de Canales locales -tipo Canal 6 de Posadas- ). Y qué decir de la textualidad performativa que acompaña los actos de campaña: ahí están -con precisión de selección intencionada- el ensamble preciso de fotos, música y textos que obedecen a un guión de efectos.

Podrá opinarse que la economía de recursos y la habilidad cada vez más generalizada para su captura y manejo es uno de los motivos de esta permanente actualidad (de fotos, música y textos: todos siendo uno) dado que no requiere los tiempos ni los presupuestos que impone por ejemplo la realización de un documental. Hecho, que también puede ser observable hoy, dada la mayor cantidad de recursos- teléfonos móviles, camáras digitales, etc) para capturar imágenes y testimonios que han posibilitado abaratar costos.

Esto es opinable pero lo que sí es indudable y efectivo, es que mantiene la magia que la imagen y el sonido provocan cuado se ve o se proyecta una foto audible.

Foto audible, sonora foto ¿por qué entonces no pensar además del uso artístico, informativo, el uso empático que genera ese esamble? ¿Acaso no se lo usa y abusa como recurso emotivo en eventos familiares -casamientos, cumpleaños, etc? ¿Por qué devaluarlo entonces -como realización menor y fútil- sólo porque plantea otro ritmo?.

Valen también en ese sentido las secuencias (cada vez más comunes de 


\section{DE HISTORIAS, MEDIOS Y REGIÓN: UNA IMPRONTA DESDE LA PRODUCCIÓN AUDIOVISUAL}

fotos, música y palabras) que se engarzan en actuales producciones documentales de afamados documentalistas del hoy (del tipo Claudia De Luque, Fabían Matus, Rodrigo Vila, por citar algunos) o las que compilan el fin de una trama del tipo Campeonato del Mundo y que reverberan con música y palabras ese momento.

Retomo la historia y mi testimonio de campo -que ahora plantea las vicisitudes de este hacer visible a la universidad en el entorno de la producción local- . El único canal que existía por aquel entonces era Canal 12 . Refiere Capaccio:

"Para trabajar había que esperar que alguna cámara estuviese desocupada, que el cameraman no estuviese requerido por otro trabajo, que terminase de desayunar, y que, en fin pusiese la buena voluntad de salir a filmar si es que a último momento el equipo no era solicitado por algún funcionario y tenía que postergarse todo. Pero si al fin las circunstancias auspiciosas se conjugaban como para que los vientos soplasen a favor de uno, todavía restaba rogar que los equipos funcionasen o que en la salida no se olvidara algún implemento técnico. Cierta vez, por ejemplo, luego de pasar toda una candente mañana filmando en lo que fuera el campo de deportes de la Laguna San José - un horrendo descampado entre pajonales hoy bajo las aguas del lago- resultó que no había registrada una sola imagen porque la casetera no tenía la batería con carga suficiente. Y así casi siempre. Al llegar al lugar de filmación con seguridad faltaba alguna ficha, alguna conexión o implemento técnico que otro operador había sacado antes para realizar tal o cual trabajo y cosas por el estilo. A ellos les daba lo mismo hacer o no hacer el trabajo, pero yo tenía asumido el compromiso y debía demostrar no sólo que me ocupaba sino hacer visible lo hecho"4

Lo cierto es que por esos lados estaba el "por verse " de la UNaM -y hago pie adrede en esa expresión local-. El "Por verse", esa materialidad de la que trata todo texto audiovisual costaba, se hacía cuesta arriba, se volvía texto burocrático. Afirma el testimonio recogido "por suerte, no quedó registro de aquellas pésimas filmaciones, mal realizadas y peor difundidas porque el Canal público jamás conservó archivos y la institución a la que pertenecía, la UNaM, era más o menos lo mismo. Cabe aclarar que para los desplazamientos utilizaba mi auto. Un Renault 12, modelo 74, gris metalizado, patente B101334 (la única que sigo recordando de todos los autos que tuve) 
ya que para disponer de un vehículo de la UNaM la tarea de gestión hubiese duplicado aquel esfuerzo y eso sobrepasaba toda voluntad puesta para trabajar. O sea, lo pesado era siempre la gestión, y lo más reconfortante el trabajo propiamente dicho cuando podía al fin concretarse algo"s .

La queja sigue y las expresiones que reflejan la orfandad de la universidad en ese contexto expresan esto :

Dice Capaccio: "No describiré en detalle lo que eran los trámites antes del trabajo en el canal, las notas formales previas que debían cursarse, las esperas, las conversaciones para explicar y que se entendiese el propósito de lo que se pretendía a madamases y mandamenos desprovistos de todo interés, los plantones, las vueltas a empezar, las impuntualidades, el trato indiferente, la falta de compromiso cuando no la irresponsabilidad lisa y llana ( por ejemplo acordar con alguien para cierto horario, llegar y descubrir que había tomado licencia y comenzar a explicarle todo a otro que no sabía nada y que se hacía cargo a desgano como de una changa paraguaya) y sin que nada de eso tuviese consecuencia alguna" 6 .

Y entonces, y más aún, el "por verse" se volvió imperativo y fue la tarea de gestión en la que se embarcaron esos docentes como el Licenciado en Comunicación Social Rodolfo Capaccio y la Licenciada en Letras María Nilda "Titita" Sodá de la Universidad Nacional de Misiones. El primero aportó el proyecto y las substanciación del mismo (fotografías, guiones y gestión); la segunda, voces y gestión.

"Todo este comentario viene a cuento para decir que comenzado el año 1980 se hizo evidente que para cualquier producción que quisiese encarar la Universidad era preferible antes de ir a pedir estos servicios, contar con los recursos propios disponibles, aunque fuesen escasos, y no depender de otros, menos con los de una institución burocrática, palaciega y servil al poder de turno como lo fue y sigue siendo Canal 12 de Posadas. En el transcurso de ese año ya me había acercado varias veces a la Secretaría de Asuntos Sociales y Culturales (que luego de la normalización en 1984, se convertiría en Secretaría de Extensión) en la calle Jujuy 192 para ver qué podría hacerse en cuanto a promoción institucional"”

$\begin{array}{ll}5 & \text { Ibid. } \\ 6 & \text { Ibid. } \\ 7 & \text { Ibid. }\end{array}$




\section{DE HISTORIAS, MEDIOS Y REGIÓN: UNA IMPRONTA DESDE LA PRODUCCIÓN AUDIOVISUAL}

Capaccio recuerda que esa institución estaba a cargo del arquitecto Tito Morales y que a la misma Secretaría se sumó enseguida la Licenciada Sodá con la que conformó un dúo de trabajo.

¿Qué hacer? se pregunta y responde el protagonista de esta historia y su testimonio cobra doble valor al articular una mística fundacional con gestión:

"Intuíamos que para cualquier cosa que pretendiésemos realizar debíamos valernos de nuestros propios recursos ¿y con qué recursos contábamos?. La Secretaría tenía una sala llamada Microcine de la UNaM. En ese lugar había funcionado el Comedor Universitario no bien fundada la universidad, pero por aquellos días había pasado a convertirse en la sede de los Talleres de Arte: pintura, danzas, expresión corporal, etc. También se daban proyecciones de películas de $16 \mathrm{~mm}$. Contábamos también con un proyector Rollei de diapositivas de un solo objetivo y yo disponía libremente de una máquina fotográfica Ashai Pentax de la Facultad de Humanidades. Pero el recurso más evidente era un camión Mercedes Benz 1114 -donación de Papel Misionero a la UNaM- , equipado con un grupo electrógeno y que contenía en su caja carrozada de aluminio equipos de sonido, bandejas pasadiscos, reflectores, etc. Un arsenal tecnológico más dispuesto para una fiesta nocturna que para realizar acciones educativas, pero un importante recurso al fin"s.

Los testimonios obtenidos en campo y que dan fuerza argumentativa a esta historia refieren que por esos días el informativo cultural de la Universidad no levantaba ni levantaría vuelo jamás. La intención no era mala pero nadie en la Universidad estaba dispuesto a contar lo que hacía para que se difundiese, de modo que la información se limitaba a un aburridísimo listado de trabajos académicos que encima se emitía por alguna emisora cuando no les quedaba nada más que informar.

Faltaban años todavía para que se creara la radio de la universidad, de modo que la Universidad dependía absolutamente de la buena voluntad de los medios locales que no la tenían mucha.

Hay, es evidente en esta historia, un carácter propositivo en todos los audiovisuales de la Secretaría de Extensión de la UNaM.. Hay una toma de posición en un debate cultural que deja entrever a sus propios adversarios teóricos y políticos (el olvido, el estado, el medio, las pautas del desarrollo,

$8 \quad$ lbid. 
la incomprensión del otro -en este caso del habitante de las fronteras- etc. y sostiene esa polémica desde un lugar poético, de poiesis. Lo hace con grados de intensidad y armas dispares como la narración, la argumentación, la descripción, la casuística, la metaforicidad, la ironía, el humor, los primeros planos, los retratos, el paisaje, la escenografía, la estrategia dramática, el diálogo, la música, la fotografía obtenida, la testimonial y la de archivo, etc.

Capaccio nos confiesa en relación con la pulseada de visibilidad o la cruzada emprendida en pos de la visibilidad que "Debíamos hacer algo más llamativo y original y pensé que a lo mejor un audiovisual, como se lo entendía por aquel entonces, es decir diapositivas proyectadas, apoyadas por una banda de sonido sincronizadas con la imagen podría ser una alternativa. En algún momento habíamos tenido una charla con el psicólogo Luis Nelly quién se refirió a las tallas de Juan de Dios Mena existentes en el Palacio del Mate y fuimos a verlas. De paso, nos acompañó Oscar Jesús Beriro, un fotógrafo de la Universidad para hacerles unas tomas"9 .

Cuenta también que las tallas por ese entonces, ni siquiera estaban expuestas sino medio arrumbadas en una sala que oficiaba a medias como depósito y oficina; ya que el Palacio del Mate, en plena época de gobiernos militares había perdido su condición de espacio de cultura para convertirse en una dependencia administrativa.

Fue la primera idea, afirma el realizador de audiovisuales, pero de a poco fue quedando claro que había una serie de temas, de índoles profundamente misionera, válidos de tratar. Nos dice en su testimonio valioso " allí estaba entre otros, el referido a los jesuitas, Horacio Quiroga, la selva, el desmonte, la transformación de la provincia y tantos otros. Pero esas ideas no aparecieron todas de golpe ni vimos tan claro de entrada lo que debíamos hacer, pero a medida que lo fuimos intentando el panorama se fue despejando"10

Ahí, en ese espacio que es el proyecto audiovisual se cuestiona y se muestra el poder en esa precisa articulación de lenguajes visuales, sonoros y gráficos. Ahí, en esa trama que resulta audiovisual hay una práctica de conocimiento, un ejercicio del mostrar, del decir lo que no puede decirse de otro modo, dadas las tensiones del campo. Es un guiño al espacio del arte (siempre entretenido y entretenedor pero también a la eficacia simbólica de objetos, palabras, sonidos y colores.

$\begin{array}{ll}9 & \text { Ibid. } \\ 10 & \text { Ibid. }\end{array}$ 


\section{DE HISTORIAS, MEDIOS Y REGIÓN: UNA IMPRONTA DESDE LA PRODUCCIÓN AUDIOVISUAL}

Los testimonios extraídos en campo dan cuenta de la relación cinética de la palabra con la imagen. En los audiovisuales, la voz, la música, la imagen de las fotos, enlaza una iconicidad que afecta, que genera afectos, en el sentido Deleziano de la afección.

Dice Deleuze ${ }^{11}$ al hablar de su imagen afección : los contenidos imagéticos afectan, tocan, producen afección... Estamos, entonces, en el terreno ( y siguiendo la línea analítica de Deleuze -aún a riesgo de una explicación silvestre- ) de contenidos imagéticos que son afecto (imagen/afección), que son pulsiones (imagen /pulsión) y que pueden ser perceptos (imagen/percepción). Entre todos estos registros se produce y se insiste en una gama de sensaciones que van desde la piedad, la simpatía, el sarcasmo, la sátira y la ternura áspera.

¿De qué manera una textualidad audiovisual expresa sentimientos? . Con música, imagen y palabras. Es la excusa de las fórmulas fijas aptas para circunstancias políticas, comerciales, deportivas y parecen recordarnos esa impronta. Articulan formas de leer y pensarnos.

$E I A B C$ de un proyecto de gestión cultural nos habla de la gestión cultural (como gran núcleo nominal), los gestores, el proyecto como partes básicas que conforman la trama. El primer hito nos conduce (dice la enunciación) a lo que hay que hacer, el segundo a quienes lo harán y el tercero a lo que se hará. Esta elementalidad referencial de pasos no se agota en la enunciación rápida (como meramente lo hacemos acá). Sabemos que implica anclajes teóricos interesantes y comprometidos; sabemos que también describe y delimita toda una inserción profesional, pero -sabemos también- que recorrer ese cause analítico sería materia de otro trabajo y no el de que aquí acercamos - en términos de registro histórico pero también de subjetividades en juego- .

Harto repetido es a la fecha el latiguillo barberiano ${ }^{12}$ de los "modos de estar juntos" y esos modos nos hablan de básicamente dos cosas: una del papel de los procesos educativos (formales e informales) para estímulo y crecimiento de las tradiciones culturales; y dos: de la socialización de los códigos de acceso y gestión de programas y proyectos para la cultura en la

11 DELEUZE, Gilles, (1981) Francis Bacon: lógica de la sensación, ed. de la différence, París. p.22

12 Cf. Martín Barbero Jesús (1988) De los medios a las mediaciones, Gustavo Gili, Barcelona, y Martín Barbero Jesús (1987) Procesos de Comunicación y matrices de cultura, Gustavo Gili- FELAFACS. México 
que estamos, y en la que contribuimos de "algún modo y por algún motivo y con algún sentido" a ese modo de de estar juntos.

La metáfora del modo remite a la proximidad y ésta implica indudablemente al espacio y al tiempo de nuestro desempeño y también refiere al por qué de esa acción dada. Dicho esto, y retomando la modulación barberiana, el desafío neural pasa por los acercamientos y distancias entre una pareja especial.

Se trata de una pareja también altamente referida en campos de estudios como los nuestros. Hablo de la que conforman la cultura y la comunicación en tanto campos de sentido y de profesionalización. Esta relación, aunque aparentemente simplista es crucial, no se puede simplemente interrogar los efectos, ni las innovaciones tecnológicas sin la misma intensidad para analizar las diferentes formas de socialización con las que enfrentamos la heterogeneidad simbólica. Sostener lo anterior implica también examinar las transformaciones que atraviesan los modos y prácticas que experimentan la pertinencia a un territorio y las maneras de poner en escena los diferentes escenarios en emergencia.

Dice Capaccio: "Debo reconocer que yo jamás había hecho un audiovisual, aunque traía mi experiencia de guiones escritos para la filmación de unos cortometrajes en el Cine Club de Mercedes y el haber participado activamente en esas realizaciones. Cuando estudiaba había visto uno hecho por Graciela Rasquetti, una compañera de la facultad, oriunda de Lobos - de la que ni siquiera fui amigo ni ha de guardar memoria de mi ni a la que recuerdo como muy simpática- sobre precisamente su pueblo. Esas imágenes acompañadas por un texto me parecieron una forma expresiva interesante y menos complicada que una película. En definitiva todo consistía en el atractivo de la imagen proyectada acompañada con un discurso apropiado para reforzar el sentido y darle coherencia y emoción (gracias Rasquetti donde quieras que estés)" ${ }^{13}$.

Hoy debemos examinar, más que nunca, la apropiación y los usos que los productores y realizadores de una materialidad tan émpatica como la audiovisual nos proponen.

"La personalidad de las tallas me motivó a escribir una historia acerca de esos personajes, atravesados por una característica común: ser todos ellos

13 Cf Testimonios de campo:Ibidem 


\section{DE HISTORIAS, MEDIOS Y REGIÓN: UNA IMPRONTA DESDE LA PRODUCCIÓN AUDIOVISUAL}

gente del litoral, gente del pueblo, de la orilla del río, del campo, con sus rasgos sobredimensionados y sus ropas coloreadas de tonos brillantes (...) La cuestión es que durante muchos días anduve con las tallas en el auto, llevándolas de paseo a la costa, a las orillas y haciéndolas posar con fondos naturales que me parecieron adecuados: chivatos florecidos, piedras de al bajada, palmeras, el brillo del río. Para las tomas privilegié los primeros planos y aún los detalles de modo de acentuar sus personalidades y el resultado fueron unas fotos en las cuales si bien se veía que se trataba de tallas el ambiente natural adecuado a la índole de los personajes las humanizaba"14.

La historia de la pre-producción y producción sigue pero sí es importante referir el momento del estreno. El realizador nos cuenta : "Se estrenó en el microcine de la UNaM, el 10 de junio de 1980. El salón estaba lleno, la gente no sabía muy bien qué era lo que iba a ver-porque eso de un audiovisual, una cosa que no era cine sino algo que se le parecía... - Pero todo salió sin inconvenientes. Se comentó mucho, El Territorio, el diario de la provincia, le dedicó una nota y a partir de ese momento 'Los Personajes de Juan de Dios Mena' fue el caballito de batalla de la Secretaría y las tallas de Mena comenzaron un proceso de revalorización que continúa”"15.

La historia re-cursada sigue, esta historia de audiovisuales continúa, y será motivo de futuras-otras entregas Sabios axiomas de la comunicación social nos dicen (desde postulados de portales actuales de medios y desde autores consagrados en la academia , como Omar Rincón) que la comunicación es entretenimiento y goce ( esto es, estéticas); que es también una narrativa ( de estructuras dramatúrgicas, géneros, formatos); que es también conexión (conversación/utilidad); que es política acceso/participación/ interacción); que es tecnologías ( de la que todos somos productores); que es expresión ( de nuestros medios, de nuestras historias, de nuestras ideas); que es cultura/identidad ( pues contamos como somos); que es innovación en perspectiva de las sensibilidades/otras y es contenido en tanto proyecto ético.

De esas cosas pretendimos hablar y a esas cosas aludimos cuando hablábamos de improntas y registros de un tiempo productivo con modulación audiovisual. Sus protagonistas fueron referentes y crearon referentes. Por ese motivo, los lineamientos generales definidos -así como también las

$\begin{array}{ll}14 & \text { Ibid } \\ 15 & \text { Ibid. }\end{array}$


formas de realización de los mismos en materializaciones concretas- fueron más bien el resultado (más que de trazos de una política diseñada institucionalmente desde la universidad) de políticas personales de gestión. Se concibió, entonces, la extensión como una función social para afirmar la imagen de la naciente universidad en el espacio misionero, pero también -y fundamentalmente- para la generación de proyectos culturales (que a la actualidad siguen abonando prácticas).

La SGEU devino así en un lugar estratégico para desarrollar políticas culturales que tuvieran que ver con la generación de proyectos y programas para la promoción cultural, la difusión, la capacitación y la información para articular los conocimientos que la universidad genera y las necesidades concretas de la población de Posadas ( con marcado énfasis en la década del ochenta). Se constituyó desde un principio en un espacio muy productivo, que llevó adelante "verdaderos mecenazgos artísticos", "mecenazgos públicos". Contribuyó muchísimo a afirmar -local y nacionalmente- la figura artística del cantautor misionero Ramón Ayala, la de los Kossa Nosstra, la del maestro Emilio Rocholl, y de muchos más sobre los que volveremos en próximos trabajos.

Sostuvo así, la SGEU, una pseudo-forma de centro de producción cultural, muy referido en la comunidad de Posadas y en la región. Fue un lugar que marcaba cierto prestigio de pertenencia, que modulaba a la vez ciertas ideas de libertad, pero que también privilegiaba ciertas visiones de enfoques teóricos y saberes por los que se deslizaban conceptos y acciones de una forma de cultura (y de hacerla, y de mostrarla y de vivirla). Conceptos y acciones. A veces, daba idea "refinada de cultura", por ejemplo en el plano de la música a fomentar, practicar, desarrollar: clásica, de repertorio, de formas corales fijas, etc. Otras jugaba con la contratara de lo refinado: apostaba a cierto influjo - definido por esos primeros pasos- como "lo under que estaba siendo impulsado por los que no sentían la centralidad de este campo y abrían propuestas desde una posición más bien de vanguardia, tal el caso de José Cáceres y su propuesta teatral o Liliana Carvallo y su Danza libre y Contemporánea”" . "Piorenizaban", dirá la Directora Teatral Carolina Gularte. Estas propuestas coexistían con otras modulaciones más románticas que trataban de recuperar "formas esenciales del ser auténtico", del

16 Fragmentos de testimonios del realizador audiovisual Nicolás Capaccio, obtenidos en campo. 


\section{DE HISTORIAS, MEDIOS Y REGIÓN: UNA IMPRONTA DESDE LA PRODUCCIÓN AUDIOVISUAL}

tipo "las representaciones de la tierra sin mal, la recuperación de la voz de los Mbyá".

El circuito productivo planteado (y los testimonios de campo lo reafirman) era más bien de índole artesanal (incluso las primeras impresiones de la modesta propuesta editorial de la Universidad permiten advertir estas marcas). En todos los casos las presentaciones y prestaciones siempre fueron gratuitas. Retomar, entonces, esta experiencia fecunda, explica develar no sólo el "de dónde venimos", "la anécdota del inicio" sino también la fuerza expresiva y material que anuda verdaderos trazos míticos por donde se desliza una épica pero también un relato de éticas que merece ser conocido.

\section{REFERÊNCIAS}

ARFUCH, Leonor (2005),Pensar este tiempo, Paidós, Buenos Aires BRUNNER José J. América Latina: Cultura y Modernidad, México, Grijalbo, 1992 GARCÍA CANCLINI Néstor "los paradigmas políticos de la acción cultural” en Políticas culturales en América Latina, Méjico, Grijalbo, 1987

MARTÍN BARBERO Jesús (1987): Procesos de Comunicación y matrices de cultura. México. Felafacs-GG.

DELGADO Nora (2007): Estereotipos de una mediación poética. Posadas. SlyP-FHyCS-U$\mathrm{NaM}$

REGUILLO Rossana. (2005): Memoria, performatividad y castástrofe. México, ITESO.

RECEBIDO EM: 16/05/2015

APROVADO PARA PUBLICAÇÃO: 02/07/2015 


\section{Nora Delgado}

Docente regular e investigadora de la Facultad de Humanidades y Ciencias Sociales (carreras de Comunicación Social) de la UNaM. Desde 1998 dirige proyectos de Investigación acreditados en la SGCyT. Directora de Becarios del CIN; del CAyCIT Mnes y de la SGCYT. 
